\title{
Comunidad rural, poder local, politización y ciudadanía: Prácticas y aprendizajes políticos en el suroeste peninsular a principios de la contemporaneidad (1808-1823)
}

\author{
José Saldaña FernándeZ
}

PALABRAS CLAVE: comunidad rural, politización, guerra de la Independencia, Trienio Liberal.

CÓDIGOS JEL: D71, D72, D74, D78.

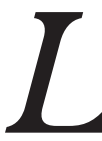

as primeras décadas del siglo XIX resultaron cruciales para la conformación de las nuevas prácticas políticas que venían a trastocar el escenario de participación público y social anterior, así como para diseñar la nueva cultura política liberal. Con todo, no resulta fácil trazar los perfiles precisos de ambos fenómenos fuera de escenarios centrales. Alcanzar un conocimiento más definido sobre estas cuestiones pasa por reconsiderar la disparidad de los escenarios, la multiplicidad de los protagonistas y la direccionalidad de los procesos. Precisamente, este trabajo analiza los procesos de politización y densificación del espacio político en el ámbito rural a partir de algunos ejemplos locales extraídos del suroeste peninsular, poniendo el acento en las prácticas y los aprendizajes generados entre 1808 y 1823, años que marcaban el inicio y el cierre de transformaciones políticas fundamentales en el tránsito entre el Antiguo y el Nuevo Régimen. Ello ha permitido constatar que las comunidades locales de ámbito rural no actuaron como meros agentes pasivos dentro de este escenario de politización, sino que participaron activamente en ese proceso de cambio mediante, por ejemplo, la puesta en marcha de una rica y compleja práctica política que descansaba en una lectura no solo amplia, sino también específica, del marco político de fondo. 


\section{Rural Community, Local Power, Politicization and Citizenship: Practices and Political Learnings in Southwestern Spain (1808-1823)}

\section{KEYWORDS: rural community, politicization, Peninsular War, Lib- eral Triennium.}

JEL CODES: D71, D72, D74, D78.

he first decades of the nineteenth century were crucial to shaping the new
political practices that both disrupted the established public and social par-
ticipation scenario and created the new liberal political culture. However, acquiring a more thorough understanding of these issues involves reassessing the disparity of the scenarios, the multiplicity of actors and the directionality of the processes. This work analyses practices that politicized and the rural political space, using local examples extracted from southwestern Spain. It emphasizes political practices and learning from 1808 to 1823, the years that marked the beginning and end of critical political transformations in the journey from the Old to the New Regime. The research verifies that local communities in rural areas were not passive agents within this scenario of politicization, but active participants. They implemented a rich, complex political practice based on a reading of the underlying political framework that was both broad and specific.

Recepción: 2019-08-07 - Revisión: 2020-11-03 - Aceptación: 2020-11-04

José Saldaña Fernández [orcid.org/0000-0002-2466-4501] es Profesor Ayudante Doctor en el Departamento de Historia Contemporánea de la Universidad de Sevilla. Dirección para correspondencia: Departamento de Historia Contemporánea, Facultad de Geografía e Historia, Universidad de Sevilla, C/ $D^{a}$ María de Padilla s/n, 41004, Sevilla. C.e.jsaldana@us.es 


\section{LA POLÍTICA EN PLURAL: LOS CAMINOS DE LA POLITIZACIÓN}

Como ha puesto de relevancia Moisés Guzmán, uno de los temas que mayor atención ha despertado en los últimos tiempos ha sido el de la cultura política en sociedades que transitaron desde un sistema de organización, valores y creencias propio del Antiguo Régimen a otro definido en términos de modernidad característico de la contemporaneidad, entre cuyas particularidades cabrían situar «la invención del ciudadano, las prácticas electivas de representación, la ritualidad cívica, la invención de héroes, la construcción de la nación y la materialización de un nuevo sujeto de la soberanía representado por el pueblo» (Guzmán Pérez, 2019: 1). A fin de cuentas, un escenario de cambio que venía a dotarse de nuevos significantes y significados en torno a experiencias que quedaban definidas bajo nuevos conceptos, protagonismos y posicionamientos en el ámbito de la gestión y la participación pública y política. En todo caso, no se trataría de un proceso cerrado y de una sola dirección.

Dentro de este escenario cabe considerar, por ejemplo, los cambios y las imprecisiones que afectarían a términos como ciudadano y ciudadanía (Horrach, 2009; Pérez Ledesma, 2012: 33-36; Salvatto \& Carzolio, 2015). Ahora bien, con independencia de los focos de atención y discusión, no debe obviarse que la conceptualización del término ciudadanía a principios de la contemporaneidad quedaba asociada de una u otra forma al desarrollo de ciertos derechos y prácticas políticas, y que, por tanto, los primeros momentos resultarían claves no solo para definir y proyectar nuevos conceptos, sino también para dotarlos de nuevos significados desde la práctica, y no necesariamente bajo un mismo y unívoco relato.Y todo ello al amparo de contextos muy ricos y complejos en los que la política y lo político adquirían una enorme importancia y donde, en consecuencia, resulta necesario cuestionarse por los caminos de la politización (Veiga, 2012: 184).

Partiendo de estas consideraciones iniciales, este trabajo pretende aproximarse a los procesos de politización y densificación del espacio público de principios de la contemporaneidad en España a partir de algunos ejemplos locales extraídos del suroeste peninsular, poniendo el acento en las prácticas y los aprendizajes generados en torno a ellos. Ahora bien, este enfoque de análisis requiere de miradas complejizadas e integradoras que no solo pongan la atención en dinámicas de participación política apoyadas en viejas y nuevas nociones y manejos, sino también en escenarios y protagonistas variados y en permanentes interacción e influencia, en los nexos y correspondencias múltiples trazados entre unos y otros, o en los momentos y ritmos diferentes en los que aquellos se producían. Desde esta perspectiva cabría delimitar algunas de las nociones y criterios que articulan este trabajo. 
El concepto de politización que manejamos alcanza una dimensión amplia al quedar vinculado con procesos de concurrencia y participación en el ámbito público, de confluencia y prácticas de poder, y de gobierno y gestión de los asuntos que afectaban a la comunidad en su conjunto. Esta perspectiva resulta coincidente con buena parte de los planteamientos desarrollados por Xosé R. Veiga (2012: 183; 2017a: 19-20), y va en la línea de otros autores que han destacado su vinculación con el concepto de política moderna, caracterizado porque el ejercicio de la política se realizaba en la esfera pública y resultaba abierto en buena medida al conjunto de la sociedad, viniendo así a alterar incluso el sistema de relación entre gobernantes y gobernados (La Parra, 2012b: 12, 16).

Ahora bien, hablar de modernización, aperturismo y densificación del espacio público no implica necesariamente acotar las experiencias a fórmulas democratizadoras, al menos de manera automática y exclusiva. Indudablemente, no deben obviarse algunas acciones en el campo de la democratización, como la representada por las prácticas de sufragio desarrolladas en el espacio latinoamericano tras la crisis de la monarquía de 1808 (Posada, 2008; Demélas \& Guerra, 2008). Al igual que otras propuestas que, próximas a un concepto más amplio de la política y de la democracia (Herrera, 2012; Herrera, Markoff \& Villa, 2013), han venido a plantear a modo de hipótesis de partida la existencia de "prácticas políticas de gestión de los recursos bastante democráticas y abiertas» en buena parte de las pequeñas comunidades rurales andaluzas a lo largo del primer tercio del siglo XIX (Acosta \& Cruz, 2012: 379). Pero tampoco hay que olvidar que la politización no avanzaba exclusivamente por el sendero liberal, de tal forma que también la contrarrevolución aportaría elementos al proceso general de politización y de modernidad política, y contribuiría de manera activa, en consecuencia, al desarrollo de dinámicas que han sido tradicionalmente identificadas con la revolución (Veiga, 2012: 185-186; Rújula \& Ramón, 2017: 6).

En definitiva, no estamos ante un fenómeno de una sola lectura y dirección. La concepción de la política como el espacio de intervención y manejo de los asuntos de la comunidad y de distribución y gestión del poder en su seno, y de la politización como el proceso de participación y movilización en el espacio público desde nuevos roles y protagonismos, terminaban amparando proyectos y acciones muy diversos y no siempre en sintonía con formulaciones democratizadoras que tendían a la igualdad en el acceso y la gestión de los recursos comunitarios. A fin de cuentas, el escenario y los medios -formales y simbólicos- de la práctica política resultaban comunes, pero no así los propósitos y sus fines, en los que cabría considerar diferentes maneras de concebir el espacio de la conducción de lo público y de la toma de decisiones en el ámbito comunitario, así como del protagonismo que en él tenían los distintos actores llamados a su concurrencia. 


\section{POLÍTICA EN TIEMPO DE CRISIS, APRENDIZAJES EN TIEMPO DE POLÍTICA}

Guy Thomson señalaba hace algo más de un lustro en su trabajo sobre el nacimiento de la política moderna en España que cualquier pueblo del tamaño de Loja hacia mediados del siglo XIX - una de las poblaciones sobre la que había centrado su análisis, de algo más de 17.000 habitantes en aquellos años- "contenía en sí mismo explosivas rivalidades personales y de partido» (Thomson, 2014:2). Ahora bien, más allá de reconocer la pertinencia de esa caracterización con respecto a pequeñas ciudades o pueblos medios y no centrales entre los años cincuenta y setenta del siglo XIX, debemos tener en cuenta, asimismo, que no estaríamos ante una foto fija y de encuadre único que retratase realidades circunscritas exclusivamente a ese tiempo y a esos espacios.

Por un lado, porque también podría definir la vida pública y política de comunidades más pequeñas determinadas por su carácter rural y su posición periférica. En tal caso, habría que reconsiderar la tradicional ruptura e incompatibilidad marcada entre el mundo rural y el urbano, donde el primero quedaría definido en clave de apatía, atraso y desmovilización (Cruz, 2012a: 25; Herrera \& Markoff, 2013: 14; Soto \& Herrera, 2014: 78).

Por otro lado, porque podría caracterizar, asimismo, el desarrollo de dinámicas políticas en el interior de la comunidad en momentos anteriores, como, por ejemplo, entre 1808 y 1823, periodo al que se asistía, en conjunción con los primeros tiempos de implantación del régimen liberal, a cambios profundos en el marco de la política y de la politización vinculados con nuevas definiciones y prácticas en el campo de la soberanía. De hecho, durante la guerra de la Independencia los nuevos compromisos de la población con las armas y la defensa de la monarquía albergaron experiencias políticas profundas y complejas, así como un significativo proceso de socialización, politización y de apertura del espacio público (Chust \& Rújula, 2017b: 63; Rújula, 2008: 43; Luis, 2009: 247; Luis, 2012: 56; La Parra, 2012a: 14). Ahora bien, no sería hasta el Trienio Constitucional cuando se diesen las condiciones más apropiadas para la consolidación de la revolución iniciada en Cádiz algunos años atrás (Moliner, 2012: 34), contexto en el que se asistiría a un aperturismo de la esfera pública más allá de lo meramente institucional y en la que los ciudadanos participarían en función de sus posibilidades e intereses en «una suerte de fiebre que parecía llevarles colectivamente a la política», mientras que la experiencia que ello suponía potenciaba asimismo el aprendizaje y la educación política de la sociedad española en su conjunto (Rújula \& Chust, 2020: 42-46).

Con todo, el aprendizaje no necesariamente guardaba relación, al menos de manera exclusiva, con aquel tiempo concreto ni con proyecciones futuras, sino que enlazaba a 
su vez con experiencias y enseñanzas que partían de momentos anteriores. De nuevo cabe dirigir la mirada sobre los años de la guerra contra el francés, un tiempo de «aprendizaje profundo y vital» (Rújula, 2012: 189) del que no quedaba al margen la propia experiencia política. Pero también cabría hacerlo sobre situaciones previas a 1808 . De hecho, el nuevo tiempo político que se abría en aquella fecha, en el que confluían antiguas y tradicionales fórmulas de protesta con nuevas maneras de concebir y hacer política (García Monerris \& García Monerris, 2009: 269), no lo haría sobre una población «huérfana de política» (Veiga, 2012: 184), sino en un terreno ya marcado por una densa y fértil cultura política popular gestada durante los siglos anteriores (Cabo \& Veiga, 2011: 27). Dentro de este marco cabría destacar las dinámicas desarrolladas en el interior de los municipios, en los que a lo largo del siglo XviII se produjeron enfrentamientos entre las facciones locales por el control del poder (Windler, 1997: 59, 416; Windler, 2007: 127).

En fin, si bien se asistía desde las primeras décadas del siglo XIX a la conformación de un nuevo espacio político que quedaba definido en términos de amplificación en cuanto a los actores y densificación respecto de sus ámbitos públicos o privados de participación, no hay que obviar que sus dinámicas y materializaciones concretas no podrían abstraerse de experiencias y aprendizajes puestos en marcha algunos años atrás. Entre otras cuestiones, el tránsito al nuevo régimen no supondría «hacer tabula rasa sin más», o al menos que este pudiese llevarse a cabo sin resistencias (García Monerris, 2018: 65). El aprendizaje de los nuevos discursos, instrumentos y mecanismos de la política no resultaba meramente receptivo y pasivo, sino algo mucho más dinámico y complejo donde se combinaban, por una parte, experiencias, costumbres, anhelos y maneras propias de entender el espacio político que fueron proyectados desde tiempo atrás en el interior de la comunidad, y, por otra, los nuevos relatos y prácticas inaugurados con el nuevo régimen y que habían sido concebidos y promovidos desde fuera de ella.

En definitiva, todos estos planteamientos sobre las características y el desarrollo de los procesos de politización y aprendizaje aplicados a las comunidades locales de ámbito rural a principios del siglo XIX nos sitúan frente a determinados elementos y enfoques que no debemos desdeñar. Entre otros, en torno al nivel de participación, dinamismo, autonomía e, incluso, originalidad desarrollado por estos espacios, y, en consecuencia, acerca del grado de complejidad y dinamismo que los pueblos llegaban a alcanzar en su interior, sobre la práctica específica y los espacios de atención preferentes del nuevo cuerpo político vecinal, o en torno a la experiencia precisa que entonces resultaba y el aprendizaje concreto que ello suponía, ya fuese desde un punto de vista individual como grupal. 
El análisis de buena parte de los aspectos señalados requiere dirigir la atención sobre instrumentos y escenarios concretos. En el primer caso, además de reconocer la centralidad que ocupaba el espacio local -en el que, como ámbito primario y natural, encontraba desarrollo buena parte de la vida política y social (Burdiel \& Romeo, 2001: 77; Guerra, 1998; Cruz, 2012b)-, habría que considerar la conformación y el discurrir de los nuevos ayuntamientos en base al desarrollo de un sistema electoral esbozado en la Constitución de Cádiz, pero que alcanzaba una versión más acabada con la publicación de algunos decretos e instrucciones posteriores (Gómez Rivero, 2015: 13-19), toda vez que representaban la versión de la revolución más extendida e identificable entre el vecindario, y que terminaban dando forma y significado a la recién estrenada ciudadanía política. Indudablemente, existían otros medios e instrumentos de politización dentro de los municipios, pero tanto su significación y proyección a lo largo del tiempo -en particular en los momentos de cambio analizados-, su papel central en la materialización y visibilidad del poder a escala municipal, así como la conservación y disponibilidad de los testimonios sobre su conformación y actuación -particularmente a través de las actas capitulares- en las diferentes coyunturas abordadas en este trabajo hacen de los ayuntamientos unos espacios fundamentales para analizar en las comunidades de ámbito local las dinámicas y los cambios sujetos a los nuevos tiempos, así como las claves internas que daban cuenta de la significación y el alcance de estos. En buena medida, además, este enfoque entronca con algunas otras propuestas y publicaciones en torno a la historia política y a la configuración del poder a escala municipal que, si bien amplían la mirada más allá de los ayuntamientos, han puesto de relevancia, sin embargo, procesos concretos de politización y de práctica política en los que es posible identificar la significación de lo local y el papel relevante ejercido por los cabildos. Es el caso de los trabajos de Xosé R. Veiga relativos a Galicia, en los que ha profundizado en torno a la "politización de lo cotidiano" y donde ha registrado una amplia gama de desencuentros en las comunidades locales, que fueron interpretados desde criterios fundamentados en la política y en lo político (Veiga, 2008, 2012, 2017a, 2017b).

En el segundo caso tomamos como referencia la situación vivida en varios pueblos del suroeste andaluz, cuyas circunstancias jurisdiccionales previas y las nuevas particularidades experimentadas durante los años de la guerra de la Independencia y del Trienio Liberal permiten trazar un relato analítico sobre el proceso de politización y reconfiguración del espacio público, del juego de intereses y tensiones que se activaría en aquel tiempo, tanto en el interior de las comunidades locales como entre poblaciones vecinas. Cartaya y Villanueva de los Castillejos, los dos núcleos rurales analizados en este trabajo, están situados en el espacio comprendido entre los ríos Odiel y Guadiana, con lo que, al no resultar ocupados ni controlados de manera permanente por los poderes franceses durante la guerra, quedaron sujetos desde un principio -aunque no sin dificultades ni obstáculos-al 
marco político e institucional proyectado por las autoridades de Cádiz. En aquellas circunstancias, la combinación de elementos del pasado y del presente, de aspectos comunes y específicos, tendría resonancias acerca de la nueva forma de participar en el escenario público y de hacer política, y, en consecuencia, sobre la manera de entender, materializar y proyectar la realidad política tanto presente como futura.

\section{LA APERTURA DEL ESPACIO PÚBLICO: REDIMENSIONANDO EL CAMPO DE LA POLÍTICA MUNICIPAL}

La villa de Cartaya contaba con 700 vecinos en el año 1810, el mismo número que se reconocía en 1787, circunstancia que mostraba un importante aumento en comparación a las cifras de 1751, cuando registraba la cantidad de 496 vecinos (Mira, 2008: 413; Mira, Villegas \& Suardíaz, 2010:35) ${ }^{1}$. En cuanto a su estructura económica, se trataría de una población fundamentalmente agrícola, si bien una parte de ella se dedicaba a labores en el mar: a mediados del siglo XVIII, según los datos que pueden extraerse del Catastro de Ensenada, contaba con 322 jornaleros y 47 marineros matriculados, cuyo jornal resultaba en uno y otro caso de tres reales diarios ${ }^{2}$; algún tiempo después, como aparece recogido en un documento de 1761 sobre rendimiento y producción de su vecindario, de los 527 individuos productores totales, más del $66 \%$ se dedicaban a la agricultura, $10 \%$ a actividades vinculadas con la industria, algo menos del $9 \%$ a la mar, poco más del $2 \%$ a la ganadería, y algo por debajo del $4 \%$ al comercio (Mira, 2008: 388-389). Las dificultades experimentadas durante la guerra de la Independencia trajeron consigo tanto pérdida de población como cambios en la economía local, tendencia que, aunque con oscilaciones, encontraba resonancia más allá de la muerte de Fernando VII (Ibid.: 393$)^{3}$. Fueron también años de cambios profundos en el entramado político y jurisdiccional, cuyos efectos se harían notar, asimismo, durante las siguientes décadas.

Cartaya, que formaba parte del marquesado de Gibraleón (bajo la Casa de Béjar), contaba con un Cabildo compuesto tanto por individuos nombrados por el titular de la ju-

1. Los tres censos reales disponibles para la segunda mitad del siglo XVIII permiten precisar algo más el número, ya que no utilizaban vecino sino habitante como unidad de medición. El censo de Ensenada muestra para 1749 una población de 2.050 habitantes, el de Aranda de 1768 una cifra de 2.220, y el de Floridablanca en 1789 elevaba el número a 2.584 (MirA, 2008: 390).

2. Archivo General de Simancas (AGS), Dirección General de Rentas, 1. ${ }^{a}$ Remesa, Catastro de Ensenada, Respuestas Generales, lib. 561, fols. 764-780.

3. A partir de registros de distinta naturaleza - de ahí la variabilidad y oscilación de los datos-, se ha constatado en 1818 la cantidad de 649 vecinos, en 1822 de 949, en 1826 de 578 y en 1836 de 538 (MIRA, 2008: 422). 
risdicción (bien directamente o a través de la fórmula mediadora de las proposiciones) ${ }^{4}$ como por sujetos cuyas vías de acceso respondían a mecanismos no vinculados con la potestad de aquel ${ }^{5}$. Esta diferente composición y origen sufriría un proceso de ajuste conforme se fuesen activando las nuevas directrices políticas traídas con el inicio de la guerra, circunstancias en la que encontrarían desarrollo, asimismo, nuevas dinámicas de confrontación dentro y fuera de la comunidad.

Las claves precisas de los primeros encontronazos parecen situarse en cuestiones de orden potestativo o de definición de campos de decisión y de actuación. En la Audiencia de Sevilla, por ejemplo, se había abierto una causa en agosto de $1809^{6}$ en la que se evidenciaban las fracturas que se habían abierto en el interior de la Corporación, así como la participación de otros miembros de la comunidad local que, actuando en combinación con ciertos capitulares, tenían capacidad de injerencia sobre el propio órgano de poder municipal. De hecho, algunos testimonios daban cuenta de la existencia de un "partido" encabezado por el cura Juan de Buelga que trataba de influir sobre las decisiones del Cabildo, situación que, según parece, no resultaba novedosa ${ }^{7}$. Con la llegada de los franceses a Sevilla y su avance hacia las tierras del suroeste desde principios de 1810 , y la proyección de tropas borbónicas y bonapartistas en la región con sus reclamaciones en metálico y en especie para sus respectivos sostenimientos, se asistiría a nuevos episodios

4. El ejercicio de los cargos se ajustaba a marcos temporales distintos: junto a los de renovación anual, que seguían el sistema de proposiciones (compuestas por la Corporación anterior pero cuya elección definitiva recaía en la casa señorial: cuatro regidores y un síndico procurador general, además de otros oficiales como regidor diputado del pósito, tesorero de propios, depositario del pósito y mayordomo del Concejo), aparecían otros como el de teniente corregidor, alguacil mayor, alcalde de la mar o alcalde del castillo, que no estaban vinculados a ese proceso de reemplazo según una temporalización fija.

5. Los cargos de diputado del común y síndico personero se renovaban anualmente por elección vecinal siguiendo un sistema de votación indirecto. No es mucho lo que se puede apuntar respecto del proceso de elección en Cartaya, sobre su materialización concreta o el marco de conflictividad política y social en el que pudo desarrollarse -en la línea de lo constatado para algunos casos estudiados en Andalucía occidental (VEGA, 1995; WINDLER, 1997; CAMPESE, 1999)-, por no contar con documentación específica. De lo que sí tenemos constancia es de algunas dificultades a la hora de llevar a cabo el recibimiento y juramento del síndico y diputado del común electos: en abril de 1805 se daba entrada a ambos cargos pese a manifestarse la tacha legal en la que concurrían y contar además con el voto en contra de los diputados del común que ingresaron en los años 1803 y 1804; y en febrero de 1809 los miembros del Ayuntamiento acordaban sustituir a la persona que había sido elegida como diputado del común por tener la tacha de que su padre era el alcalde del castillo. Archivo Municipal de Cartaya (AMC), Actas Capitulares, leg. 9, s. fol.

6. Archivo Diocesano de Huelva ( $\mathrm{ADH})$, Cartaya, sección Justicia, serie Criminales, leg. 12, exp. 55, fol. 1.

7. En uno se apuntaba que el cura Juan de Buelga había sido «cabeza de un partido» durante muchos años. Ibid., fol. 13. Un análisis sobre el concepto de partido para aquel contexto, en FERNÁNDEZ TORRES (2012). 
de tensión dentro de la comunidad local, en los cuales no faltarían en ocasiones las denuncias por colaboracionismo y afrancesamiento ${ }^{8}$.

Ahora bien, más allá de estas muestras de confrontación en el ámbito de la gestión municipal, sería en los últimos meses de 1811 cuando comenzaron a detectarse de manera más nítida algunos síntomas de apertura de un nuevo escenario. En septiembre de aquel año se llevaba a cabo la elección de varios representantes para que intercediesen frente a las autoridades de Sevilla respecto de los suministros hechos a las tropas imperiales y acerca de la contribución mensual asignada a la villa. A ese acto no solo concurrieron algunos miembros del Cabildo, sino también «un número crecido de vecinos»" ${ }^{9}$ y a su finalización se marcaba explícitamente la distinción entre los representantes que resultaban elegidos: uno por el Ayuntamiento y otros dos por nombramiento del pueblo ${ }^{10}$. En un ambiente de cambios, en el que entre otras cuestiones habría que considerar los efectos de la normativa de las Cortes sobre el tradicional marco jurisdiccional, se vislumbraba, asimismo, una cierta apertura en la gestión de los asuntos públicos de Cartaya mediante la incorporación en determinadas cuestiones de interés para toda la comunidad del parecer de individuos que no formaban parte del Ayuntamiento, así como de sus votos con independencia de este.

A mediados de octubre de 1811 volvía a reunirse un cabildo abierto en el que participaron tanto los miembros del Ayuntamiento como un crecido número de vecinos con el objeto inicial de atajar las dificultades por las que pasaba la villa mediante la venta de las tierras de propios. Sin embargo, por iniciativa del pueblo asistente se alcanzaron una serie de acuerdos que, al margen de afectar a otras muchas parcelas de la economía municipal, vinieron a reorganizar el sistema de relación con los pueblos circundantes -en un apartado tan importante como el del campo común-y el panorama del poder a nivel local. En aquel contexto se creaba una Junta de cinco personas que, actuando en representación del pueblo, quedaba encargada de los suministros, contribuciones, repartimientos y demás cuestiones que tuviesen relación con estos compromisos a los que debía atender la villa ${ }^{11}$. En consecuencia, el vecindario asumía a través de una nueva fórmula

8. Un regidor del Ayuntamiento de Cartaya, que ejercía entonces la real jurisdicción ordinaria de la villa, fue denunciado en enero de 1811 por uno de sus vecinos de actuar en connivencia con los ocupantes franceses. Archivo Municipal de Isla Cristina (AMIC), Autos de oficio, leg. 1339, s. fol.

9. AMC, Actas Capitulares, leg. 9, s. fol.

10. Por el Ayuntamiento fue nombrado el regidor decano, y por el pueblo lo serían un presbítero y la persona que ostentaba el cargo de alcalde del castillo y que con anterioridad había ejercido como regidor para el año 1801 y desde 1804 como alcalde de la mar. AMC, Actas Capitulares, leg. 9, s. fol.

11. Contaba entre sus miembros con el cura Juan de Buelga, quien había sido acusado en un contencioso anterior, ya comentado, de encabezar un partido durante muchos años. Junto a él y a otro 
institucional la dirección de las cuestiones más importantes del momento, quedando el Cabildo devaluado en lo que respecta a su tradicional campo de acción, más si cabe si tenemos en cuenta la capacidad que la Junta se otorgaba para auditar la actuación de algunos de los miembros del Ayuntamiento ${ }^{12}$.

En definitiva, la realidad político-institucional de Cartaya entre 1811 y mediados de 1812 reflejaba un cambio en relación a los años anteriores no solo en referencia a la mayor autonomía de la que fueron dotándose sus órganos de gobierno municipal, sino también por el desmantelamiento de la estructura señorial que hasta entonces había amparado su propia relación con el entorno. Ambas circunstancias no harían sino afianzarse desde el último tercio de 1812, una vez entrasen los nuevos concejales con arreglo a lo recogido en la Constitución de Cádiz. Entre las acciones del nuevo Ayuntamiento cabría destacar la comunicación que dirigía al Consejo de Regencia solicitando la aprobación, aún pendiente, de la venta de tierras que se había acordado en octubre de 1811 para atender a las urgencias financieras del momento, y que argumentaba en los beneficios económicos que había generado, en la tranquilidad del vecindario y la seguridad en sus propiedades $^{13}$.

Por otro lado, la equiparación de derechos y la igualdad de condiciones en el uso y el aprovechamiento de los campos comunes fueron objeto de atención en momentos anteriores, si bien alcanzaban a partir de entonces un especial protagonismo. De hecho, si ya el cabildo abierto de octubre de 1811 recogía alguna pretensión respecto de los derechos sobre los productos del campo común que compartía con otros pueblos del entorno, el tratamiento que sobre este asunto se hacía a partir de septiembre de 1812 adoptaba una línea argumental que incorporaba nuevos elementos legales y legitimadores vinculados con el texto constitucional y que venía a proyectar un marco de relación intercomunitaria basado en la equiparación y la simetría que superaba la tradicional articulación del espacio y del poder cultivada hasta entonces.

presbítero, se encontrarían varios oficiales de la milicia honrada de la villa, uno de los cuales había ejercido además como diputado del común en 1807 y 1808 . Otro de sus componentes, que aparecía definido en la documentación como "matriculado", había ejercido como regidor del Ayuntamiento en 1800,1804 y 1807 .

12. 16 de octubre de 1811. AMC, Actas Capitulares, leg. 9, s. fol.

13. 12 de noviembre de 1812. AMC, Actas Capitulares, leg. 9, s. fol. 
El desencuentro con Gibraleón, la antigua capital del marquesado ${ }^{14}$, afectó a diversos escenarios y situaciones; por ejemplo, a la concesión de derechos de explotación sobre determinados productos en lugares que hasta entonces formaban parte del campo común. En aquel contexto, ante el permiso otorgado por el alcalde de Gibraleón a un particular para que vendiese aguardiente y otros licores en el sitio de El Rompido, las autoridades de Cartaya no solo denunciaron que aquel hubiese asumido una jurisdicción superior a la que entonces le correspondía, sino que caracterizaron las relaciones de estas villas en el pasado bajo referencias a la opresión y la esclavitud ${ }^{15}$.

La nueva articulación del espacio continuó generando desencuentros en los siguientes meses, durante los cuales el Ayuntamiento de Cartaya asumía un claro compromiso con la igualdad y la proporcionalidad entre los pueblos en el uso y el disfrute de los recursos que compartían, y con la equivalencia y la simetría en el acceso a los instrumentos y la acción de gobierno. Sin embargo, una vez que se produjo la caída del sistema en 1814 y se reinstauró el Ayuntamiento de 1808, ese activismo perdió fuelle, al menos en lo que respecta a las convocatorias impulsadas desde Gibraleón para tratar asuntos relativos al campo común. No así sobre otros símbolos y escenarios de poder, sobre los que se ensayaron revitalizadas resistencias, de tal forma que no quedaron totalmente desactivadas las aspiraciones de mayor independencia respecto del marco jurisdiccional inmediato. Algunos hitos vienen a mostrar cómo la vida de la comunidad local siguió canalizándose a partir de ciertos anhelos que habían tomado especial proyección durante la etapa constitucional (Saldaña, 2016b).

\section{LA DENSIFICACIÓN DEL ESCENARIO PÚBLICO: RECONSIDERANDO LA UNIDIRECCIONALIDAD DEL PROCESO}

Villanueva de los Castillejos contaba en 1810 con unos 550 vecinos, cifra que evidenciaba una notable pérdida de población respecto de registros anteriores: 885 en 1780, 702 en $1787 \mathrm{y}$, según lo consignado en la documentación municipal, rondando el millar de vecinos en 1809 (Mira, Villegas \& Suardíaz, 2010: 35) ${ }^{16}$. A pesar de los números que presentaba desde mediados del siglo XvIII, que la situaban como la villa más poblada del mar-

14. El crecimiento demográfico de Gibraleón resultó más moderado que el de Cartaya, de tal forma que desde las últimas décadas del siglo XviII esta última villa incluso lograba posicionarse por encima en número de vecinos (MIRA, Villegas \& SuARDíaz, 2010: 35).

15. 13 de marzo de 1813. AMC, Actas Capitulares, leg. 9, s. fol.

16. En número de habitantes, el Catastro de Ensenada de 1752 presentaba la cifra de 1.922, el de Aranda de 1768, de 3.258, y el Censo de Floridablanca de 1787, de 3.160 (GoRDo \& NúÑEZ MÁrqueZ, 1999: 636). 
quesado de Gibraleón, durante la guerra de la Independencia, particularmente desde 1810, redujo drásticamente su población: en junio de 1815 sus regidores se lamentaban de que su vecindario se había quedado reducido a una tercera parte del que tenía antes de la contienda, y que además era "la más pobre y desdichada" (Mira, Villegas \& Suardíaz, 2010: 216). Aunque el número de vecinos se iría recuperando paulatinamente durante los próximos años, nuevas oscilaciones y descensos en las siguientes décadas no permitirían que alcanzase las cifras de los primeros tiempos de la guerra durante la primera mitad del siglo XIX (ibid.: 47).

Los efectos del conflicto también se harían notar en su estructura económica. Villanueva de los Castillejos contaba hacia mediados del siglo XviII, según los datos que pueden extraerse del Catastro de Ensenada, con una economía de base principalmente agraria, en la que se cultivaba una superficie de más de dos mil fanegas (con un porcentaje de aprovechamiento del territorio por encima del $85 \%$, en su mayor parte para el cultivo de cereal), y con un elevado número de jornaleros: 482, que representaban algo más del $75 \%$ de su población activa, y que cobraban un sueldo diario de 3,5 reales, por encima de otros pueblos del entorno (ibid.: 37-42). En el contexto específico de la guerra, además de los enfrentamientos puntuales entre los ejércitos o de los efectos de su posicionamiento como centro de operaciones de las tropas fernandinas, el vecindario sería testigo directo de la presencia de contingentes militares de uno y otro bando, y de sus presiones para obtener requerimientos y exacciones. La economía de la villa se vería entonces claramente afectada, llegando sus autoridades a manifestar con fecha 16 de mayo de 1813 que había quedado «este pueblo en la mayor miseria, pobreza y dolorosa indigencia", y que junto a faltarle muchos habitantes, sus bienes habían quedado reducidos «a menos de la décima parte que antes de la guerra tenían» ${ }^{17}$.

En paralelo se asistiría además a transformaciones en su estructura y dinámica políticas. Villanueva de los Castillejos también formaba parte del marquesado de Gibraleón y estaba sujeto a la casa de Béjar, que ejercía la potestad de designación última respecto de la mayor parte de los cargos del Cabildo ${ }^{18}$. Sin embargo, esta situación se vería alterada tras el decreto de las Cortes de 6 de agosto de 1811 sobre la abolición de los señoríos, a partir del cual se debía elegir a los miembros del Cabildo según el procedimiento seguido en los pueblos de realengo (Morán, 2011: 259). Esta nueva circunstancia generaría dis-

17. Archivo Municipal de Villanueva de los Castillejos (AMVC), Actas Capitulares, leg. 11, s. fol.

18. El titular de la jurisdicción seleccionaba los nombres a partir de la propuesta (dos para cada puesto) remitida por el Ayuntamiento saliente: dos alcaldes ordinarios, cuatro regidores, un alguacil mayor, un procurador síndico general, un tesorero del Concejo, un padre general de menores y un depositario del pósito. A estos habría que sumar dos diputados del común y un síndico personero que accedían por elección del vecindario. 
crepancias internas con respecto a la forma concreta de aplicación. Al finalizar el año de su ejercicio, los alcaldes y regidores salientes limitaron el acto de elección al estricto marco del Cabildo, de tal forma que el 7 de enero de 1812, considerando la despoblación de la villa y los perjuicios ocasionados por la dilación del proceso de elección, y deseando asimismo que los nuevos empleos recayesen "en personas veneméritas y de toda providad», acordaron los nombres que formarían parte del Ayuntamiento para el nuevo año ${ }^{19}$.

Los primeros en mostrar ciertas precauciones en torno al formato de elección adoptado serían los mismos que habían sido agraciados con el nombramiento. En el acto de posesión de los cargos, cuya asistencia resultó escasa, el elegido en calidad de alcalde de segundo voto sostuvo su rechazo ante aquella "elección arbitraria", ya que no se habían hecho propuestas de personas dobles ni se habían remitido al tribunal territorial ${ }^{20}$. Otras acciones promovieron, sin embargo, transformaciones más radicales y permitieron redimensionar el espacio político de la villa a partir de la ampliación de la base participativa de su vecindario. En un escrito firmado con fecha de 18 de enero de 1812 por cuatro vecinos de la localidad ${ }^{21}$-según sostenían, actuando «a nombre del Pueblo»- y remitido a los diputados del común, a quienes reconocían como «únicos Representantes del Público en esta Villa», se denunciaba la "miserable situación» en la que se encontraba el pueblo y la necesidad de "hacer elección popular de todos los empleos de justicia» ${ }^{22}$. La petición encontró buena acogida en los diputados del común, quienes promovieron de manera inmediata la elección de alcaldes y regidores. El día 19 de enero, en un acto al que había sido convocado "todo vecino sin ecepción de clases» y al que asistieron finalmente unos cincuenta vecinos, se llevaba a cabo la elección del nuevo Ayuntamiento, cuya composición terminaba siendo diferente al conformado en el proceso anterior, el del 7 de enero, que había quedado circunscrito en exclusiva a los miembros del Cabildo ${ }^{23}$.

19. 7 de enero de 1812. AMVC, Actas Capitulares, leg. 11, s.f. Un análisis más detallado sobre el contenido de este epígrafe, en SALDAÑa (2016a).

20. Documento suelto, sin fecha, aunque algunos indicios permiten situarlo en enero de 1812 . AMVC, Actas Capitulares, leg. 11, s. fol.

21. Tomando como referencia la composición del Ayuntamiento desde 1800 en adelante -reconstruido en buena parte, ya que las fuentes utilizadas no han permitido hacerlo de manera completa-, podemos identificar a uno de los firmantes en el Cabildo de 1807 en calidad de alguacil mayor. AMVC, Actas Capitulares, leg. 10, s. fol.

22. El documento refería además que "el pueblo está yermo», y que "constando de mil vecinos hútiles, está reducido a doscientos de la clase opuesta». AMVC, Actas Capitulares, leg. 11, s. fol.

23. El elegido en calidad de regidor decano aparecía entre los capitulares de 7 de enero, si bien en el cargo de tesorero del Concejo. Además, de los diez componentes del nuevo Ayuntamiento, solo es posible identificar a dos en labores de gobierno con anterioridad a esa fecha: el regidor decano, que había ejercido como regidor en 1807, y el regidor cuarto, que había ocupado un cargo similar en 1806. 
Bajo el tiempo de gobierno del nuevo Ayuntamiento, y con objeto de atender a las obligaciones del suministro a las tropas, se llevaría a cabo la venta del fruto de la bellota de la dehesa concejil por cinco años. Para este proceso, los miembros del Cabildo se hacían acompañar por más de veinte individuos - «todos de esta vecindad, de la mayor providad y representación pública» ${ }^{24}$-, y acordaban que la adjudicación recayese en aquellos que dispusiesen del importe a la mayor brevedad posible, entre cuya nómina se encontrarían algunos familiares de los capitulares o antiguos cargos del Ayuntamiento (Mira, Villegas \& Suardíaz, 2010: 212). De la misma forma, el Cabildo impulsaba la creación de una Junta de Subsistencia que debía encargarse de la gestión de los suministros a las tropas, en cuyo acto volvió a acompañarse de las principales personas del vecindario: entre los seis individuos «de toda probidad y confianza» que fueron nombrados, se localizaban dos que habían firmado el documento de enero a partir del cual se había iniciado el proceso de elección popular que condujo a la conformación del actual Ayuntamiento ${ }^{25}$.

En todo caso, a pesar del sistema de conformación seguido, este Ayuntamiento se vería afectado por el proceso de renovación con anterioridad a que se extinguiese su año natural de ejercicio. El nuevo Cabildo, sujeto al procedimiento de elección marcado por la Constitución de Cádiz, tomaba posesión el 4 de noviembre de $1812^{26}$. Además de no contar entre sus miembros con sujetos que habían ejercido la representación en el Ayuntamiento precedente ${ }^{27}$, en un ejercicio de claro distanciamiento respecto de la actividad desarrollada por este llegaba a acusar a sus componentes de negligencia, omisión y desatención en el cumplimiento y la ejecución de muchas de las órdenes que habían recibido en el tiempo de su gobierno. Al margen de la naturaleza y el contenido preciso de los problemas denunciados, las críticas pudieron también responder a los desencuentros que se venían dando en el interior de la comunidad entre grupos o individuos que contaban con intereses no solo diferentes, sino incluso enfrentados; por ejemplo, el síndico del Ayuntamiento denunciaba en diciembre de 1812 los desórdenes y los daños que se estaban generando en el común del vecindario «por varios particulares de él, ya por ignorancia o ya por malicia", en escenarios como el de la distribución de los arbolados y los terrenos para la labranza en el campo común, las labores de preparación del suelo para la agricultura o sobre la venta en ciertos ramos; actuaciones que, según refe-

24. 11 de junio de 1812. AMVC, Actas Capitulares, leg. 11, s. fol.

25. 12 de julio de 1812. AMVC, Actas Capitulares, leg. 11, s. fol. Ninguno además con experiencia política previa, según los datos que hemos podido manejar desde 1800 en adelante.

26. AMVC, Actas Capitulares, leg. 11, s. fol.

27. No así respecto de ayuntamientos anteriores: el alcalde ya había desempeñado ese cargo en 1804; en cuanto a los regidores, uno había ejercido como tal en 1808, otro como alcalde en 1810 y un tercero como diputado del común en 1800 y síndico personero en 1805; y el síndico personero había ocupado ese mismo puesto en 1809 . 
ría, no eran conformes «al interés general de todos» ni tenían en cuenta los «perjuicios que hacen en todo el común» ${ }^{28}$.

El clima de tensión volvía a ponerse de relevancia a finales de 1813, durante el proceso de elección para la formación del Ayuntamiento del siguiente año. Los nueve electores se reunían el 19 de diciembre en una junta presidida por el alcalde y a la que asistieron también los dos escrutadores y el secretario del Ayuntamiento ${ }^{29}$, y de la que salieron elegidos a "pluralidad absoluta de votos» los nuevos miembros de la Corporación que ocupaban el cargo el primer día de $1814^{30}$. Ahora bien, habría que esperar más de un mes para que el nuevo Ayuntamiento tomase posesión definitiva por haberse declarado la nulidad de esa elección. Ello encontraba explicación en la denuncia elevada por diecisiete particulares sobre algunas irregularidades y atropellos cometidos contra ellos en las elecciones del 12 de diciembre, aquellas en la que se designaba la nómina de electores. En los poderes otorgados por los denunciantes se hacía referencia a que fueron "privados de los derechos de ciudadanos» $\mathrm{y}$, como tal, apartados del proceso de elección de forma escandalosa, unos acusados de "seductores» y otros "por seducidos", así como que sus protestas «fueron despreciadas y desatendidas» y que ni tan siquiera fueron "oídos ni escuchados» en sus reclamaciones, por lo que resolvieron entonces retirarse a sus respectivas casas para evitar una agitación mayor ${ }^{31}$. Entre los sujetos excluidos se localizaban individuos que habían tenido una proyección y presencia pública de importancia en momentos anteriores ${ }^{32}$, algunos de los cuales incluso habían ejercido cargos en el Ayuntamiento ${ }^{33}$.

Aunque el proceso electoral había seguido adelante con la reunión de los electores el 19 de diciembre, el gobierno político de la provincia atendía a la solicitud de los reclamantes y disponía la realización de nuevas elecciones, para lo cual establecía la reposi-

28. 7 de diciembre de 1812. AMVC, Actas Capitulares, leg. 11, s. fol.

29. AMVC, Actas Capitulares, leg. 12, s. fol.

30. Parte de los nuevos componentes habían ejercido en corporaciones anteriores: uno ocupó el puesto de alcalde en 1807 y 1811, otro ejerció como regidor en 1808, otro como diputado en el Ayuntamiento que había sido elegido por el vecindario el 19 de enero de 1812, y un cuarto actuó como alcalde en 1807 y fue designado síndico procurador general en el Ayuntamiento conformado el 7 de enero de 1812, aunque no llegó a ejercer.

31. Archivo de Protocolos Notariales de Ayamonte (APNA), Escribanía de Manuel Mateo Yáñez Blanco, El Almendro, 1813, leg. 1142, fols. 89-91, 93-95, 95-98.

32. Dos de ellos participaron en el proceso de elección del 19 de enero de 1812, y otros dos formaron parte de las reuniones del 11 de junio y 12 de julio de aquel año en las que se acordaron la venta del fruto de la bellota y la formación de la Junta de Subsistencia respectivamente. AMVC, Actas Capitulares, leg. 11, s. fol.

33. Uno ejercería como alcalde en 1802,1804 y 1809, otro en 1801 y 1805 , otro en 1806 y 1811 , $\mathrm{y}$ un cuarto en 1808. 
ción de algunos cargos que habían ejercido en el curso anterior ${ }^{34}$. El día previo a la celebración de la junta parroquial para la designación de los nuevos electores, los capitulares restablecidos en sus funciones acordaban algunas medidas para «evitar todo motivo que pueda perturbar el orden y la libertad del ciudadano en dichas elecciones»: por una parte, prohibiendo «absolutamente el uso común de los licores», con medidas concretas con respecto al arrendador del estanco del aguardiente y a los expendedores de vinos; $y$, por otra, insistiendo en que el «público observe toda pasificación y armonía», y que, en consecuencia, se alejase de "Juntas y tertulias por la época de las elecciones»" 35 .

El listado de elegidos en este segundo proceso no variaba con relación al anterior. Según parece, las medidas adoptadas permitieron encauzar las elecciones al margen de sobresaltos, garantizando además la incorporación en el nuevo Ayuntamiento de los individuos que habían salido electos en el proceso antecedente. Pero ello no significa, al menos necesariamente, que se hubiese disuelto el clima de enfrentamientos previos que pudo conducir a la nulidad del proceso de elección anterior, toda vez que esta circunstancia también podía encontrar explicación en la limitada capacidad de influencia con la que terminaban contando los supuestos instigadores, o en su menor pujanza con respecto a otras fuerzas o grupos de intereses de la localidad.

En el acto de recibimiento y juramento, supervisado por un comisionado nombrado por el jefe político de la provincia, los nuevos miembros se comprometían no solo a "cumplir y hacer cumplir la Constitución política y los Decretos Nacionales", sino también a mirar "por el bien del Público y por su tranquilidad»" ${ }^{36}$. Entre las primeras medidas de la nueva Corporación cabe destacar la promulgación de un auto de buen gobierno que tenía por objeto "evitar todo género de males, excesos y desarreglos», en el que se reprobaba la objeción y la crítica contra las «operaciones y providencias» del Ayuntamiento, mientras se cerraba con una llamada a que todos los vecinos y moradores observasen "rígidamente nuestras leyes, órdenes y providencias del gobierno nacional, constitucional y municipal, conservándose en paz y tranquilidad» ${ }^{37}$.

Las continuas referencias al orden y la quietud pública se desarrollaron, no obstante, en un contexto especialmente comprometido, en el que incluso algunos sujetos abando-

34. Escrito del jefe político de la provincia de mediados de enero de 1814 en el que hacía referencia a una orden de su antecesor de 26 de diciembre de 1813. AMVC, Actas Capitulares, leg. 12, s. fol.

35. 22 de enero de 1814. AMVC, Actas Capitulares, leg. 12, s. fol.

36. AMVC, Actas Capitulares, leg. 12, s. fol.

37. 2 de febrero de 1814. AMVC, Actas Capitulares, leg. 12, s. fol. 
naron el pueblo y se avecindaron en otras villas del entorno. Ahora bien, con ser significativo el número de vecinos que se trasladaban -que llegaba a alcanzar un total de diecisiete-, lo más llamativo sería no solo la forma en la que estos gestionaban la salida, sino también la naturaleza y la condición social que les definían. Por un lado, porque la solicitud de avecindamiento se hizo de manera grupal, en la que la mayor parte de ellos, "consultando la mejora de nuestros intereses», habían resuelto establecer su residencia en Gibraleón ${ }^{38}$. Por otro, porque los sujetos que trasladaron sus domicilios finalmente a Gibraleón y San Bartolomé de la Torre "eran todos los de mayores riquezas, los más pudientes y principales contribuyentes" ${ }^{39}$. Entre ellos se encontraban algunos sujetos que habían ejercido como alcaldes o regidores con anterioridad ${ }^{40}$, varios de los cuales, además, habían tenido un papel muy destacado en el contencioso que propició la nulidad de las elecciones de diciembre de 1813 y la apertura del segundo proceso de elección de principios del siguiente año.

Las causas de este traslado no quedaban recogidas en las fuentes, si bien el desencadenante de ese "grave desorden" ${ }^{41}$ podría estar vinculado con cuestiones fiscales y hacendísticas ${ }^{42}$. No obstante, en el fondo se vislumbran dinámicas sociales y políticas muy complejas, con fracturas dentro de la comunidad local de enorme proyección y trascendencia, y en las que parte de los sectores más acaudalados habían quedado finalmente con limitada capacidad de ascendencia y control en torno a las medidas impulsadas por el Ayuntamiento. En caso contrario, y antes de recurrir a la emigración, podrían haber arbitrado algún mecanismo que resultase más acorde a sus intereses.

Por otro lado, la salida de parte de los sujetos más acaudalados tendría importantes consecuencias para los intereses concretos de la comunidad vecinal en su conjunto, principalmente en el apartado de los compromisos fiscales de la villa. Esta circunstancia propiciaría incluso la puesta en marcha de nuevos espacios de confluencia y deliberación, como, por ejemplo, el cabildo abierto celebrado a finales de julio de 1814 en el que, si-

38. 24 de febrero de 1814. Archivo Municipal de Gibraleón (AMG), Actas Capitulares, leg. 14, s. fol.

39. Escrito del Ayuntamiento de Villanueva de los Castillejos dirigido al Subdelegado de Rentas del Partido de Ayamonte, 4 de abril de 1814. AMVC, Actas Capitulares, leg. 12, s. fol.

40. Uno en 1802,1804 y 1809 , otro en 1806 y 1811 , y un tercerdo en 1810 ; otro individuo como regidor en 1806 .

41. En esos términos era calificado aquel suceso por el Ayuntamiento de Villanueva de los Castillejos ante la Subdelegación de Rentas del Partido de Ayamonte. AMVC, Actas Capitulares, leg. 12, s. fol. 42. En la solicitud de avecindamiento en Gibraleón se hacía mención a que una vez resuelto el cambio de domicilio no debían ser incluidos ni considerados para ninguna carga vecinal correspondiente a Villanueva de los Castillejos. AMG, Actas Capitulares, leg. 14, s. fol. 
guiendo las órdenes del intendente sobre el pago que debía satisfacer la villa para la manutención de las tropas, se llegó a reunir, superando el número de noventa, «la más sana parte de este Pueblo, vecinos estantes, habitantes y hacendados de las varias clases y profeciones de que se compone» ${ }^{43}$.

Esta nutrida reunión permite, asimismo, reconsiderar otras facetas de la vida comunitaria tras la restauración emprendida por Fernando VII varios meses atrás. No en vano, entre los asistentes se localizaban algunos sujetos que habían protagonizado el desavecindamiento del febrero anterior. En este sentido, los cambios derivados de la caída del régimen constitucional $-\mathrm{o}$ al menos las expectativas generadas entre ciertos individuos $\mathrm{o}$ grupos ante el nuevo marco político-institucional-, pudieron auspiciar algún tipo de reestructuración en el entramado social y vecinal de la villa, en correspondencia, además, con la proyección de un nuevo relato sobre la etapa constitucional. Las declaraciones del Ayuntamiento restaurado de finales de agosto insistían en que «por causa de las reboluciones y disturbios que se han padecido» se encontraban «los puntos más interesantes de este gobierno en la mayor decadencia y desarreglo", de ahí que resultase necesario y urgente ponerlos «en mayor orden y economía posible» 44 . La identificación entre los términos revolución, disturbio, decadencia, desarreglo o desorden anticipaba, pues, un nuevo tiempo, con repercusiones incluso en la propia forma de concebir y proyectar la participación en el campo de la política y la gestión de lo público durante los siguientes años.

\section{LOS PERFILES DEL APRENDIZAJE: REINTERPRETANDO EL ESPACIO DE LA POLÍTICA MUNICIPAL}

Los casos de Cartaya y Villanueva de los Castillejos permiten situar el foco de atención sobre los procesos de cambio y reajuste políticos impulsados entre 1808 y 1814 desde la perspectiva de las comunidades locales de ámbito rural, cuestionando así algunas de las líneas de interpretación que han venido definiendo tradicionalmente el papel y la relevancia de esos espacios dentro del marco general de fondo. Dinámicas que, por otro lado, terminaban por afectar al campo de la política municipal más allá de los años concretos de la guerra, ya sea, por ejemplo, en el terreno de la autonomía y la reafirmación de la comunidad local frente al marco señorial tradicional, o ya sea sobre las nuevas prácticas políticas implementadas en torno a la conformación y la gestión del poder municipal. En líneas generales, los escenarios locales, además de contribuir a definir el nuevo marco público de participación ciudadana, se erigieron en piezas fundamentales para el aprendizaje de buena

43. 31 de julio de 1814. AMVC, Actas Capitulares, leg. 12, s. fol.

44. 30 de agosto de 1814. AMVC, Actas Capitulares, leg. 12, s. fol. 
parte de las prácticas que lo sustentaban. Otra cuestión sería determinar el sedimento que quedaba de este aprendizaje y su repercusión sobre contextos políticos posteriores. Ciertos acontecimientos ocurridos en los siguientes años aportan algunas pistas al respecto.

El Ayuntamiento de Cartaya había puesto especial cuidado durante la etapa constitucional en neutralizar los mecanismos que daban continuidad al marco señorial extinto y que establecían relaciones jerárquicas entre la villa de Gibraleón y el resto de los pueblos que conformaban el marquesado. Sin embargo, la vuelta al absolutismo en 1814 no acabó con esas pretensiones de igualdad, circunstancia que encontraba acomodo además en el mismo modelo de restauración puesto en marcha desde instancias superiores de poder, el cual restringía el campo de acción de los antiguos señoríos jurisdiccionales y proyectaba las instituciones de la Corona sobre los marcos antes a ellos sujetos. Esta nueva circunstancia albergaba, además, nuevos episodios de confrontación, tanto dentro como fuera de la comunidad local. Así, por ejemplo, el nombramiento en marzo de 1815 de un corregidor para el marquesado de Gibraleón trajo consigo un contencioso entre este y el Ayuntamiento de Cartaya, que defendía su independencia y separación del marco jurisdiccional tradicional y que, como parte ahora de las villas exentas que estaban sujetas a la jurisdicción real ordinaria, debía actuar al margen de la potestad de dicho cargo ${ }^{45}$. Esta disputa se extendería durante algún tiempo, incluso tomaría nuevos impulsos y significados tras el nombramiento de un alcalde mayor que debía ejercer de presidente de la Corporación, pero cuya procedencia resultaba ajena y extraña a la comunidad local (Saldaña, 2016b: 95-97).

En ese contexto también habría que situar el acuerdo adoptado el 15 de julio de ese mismo año con objeto de solicitar a la autoridad superior el nombramiento de dos alcaldes ordinarios tomando en consideración tanto la práctica seguida en el pueblo desde el tiempo de su conquista hasta el año $1657^{46}$, como la reincorporación de esa figura en el Ayuntamiento desde 1812 según resolución del Consejo de 20 de noviembre del año anterior ${ }^{47}$. Algunos meses después, una vez producido el nombramiento por Real Cédula del alcalde mayor, el Ayuntamiento manifestaba su acatamiento, aunque sin perjuicio del recurso que tenía pendiente sobre el nombramiento de alcaldes ordinarios ${ }^{48}$.

45. AMC, Actas Capitulares, leg. 9, 1815, fols. 6-7.

46. El Diccionario de Tomás López recogía que «hasta cerca de los fines del siglo anterior, era de dos alcaldes ordinarios con los referidos regidores, mas dichos alcaldes en el reinado del señor Don Felipe IV, se suprimieron, por servicio pecuniario que hizo la Casa de dicho Señor Excmo. y en fuerza del cual logró suprimirlos y que en su lugar hubiese dicho teniente» (RUIZ GonZÁlEZ, 1999: 111).

47. AMC, Actas Capitulares, leg. 9, 1815, fol. 10.

48. 17 de octubre de 1815. AMC, Actas Capitulares, leg. 9, 1815, fol. 15. 
Con todo, no sería hasta la vuelta al modelo constitucional doceañista entre 1820 y 1823 cuando se asistiese a cambios sustantivos en el organigrama de cargos de la Corporación de Cartaya, siguiendo lo marcado por la Constitución en esta materia. Por otro lado, durante el Trienio volvía a ponerse de relevancia la defensa de la gestión compartida -sin jerarquías ni privilegios predeterminados- del campo común adscrito al extinto marquesado. Por entonces afloraban de nuevo las tensiones respecto de Gibraleón, la antigua cabeza del territorio jurisdiccional de la casa de Béjar, en una suerte de reedición de acciones ya proyectadas durante los años de la guerra de la Independencia, y donde, por tanto, estas tomaban cuerpo y adquirían nuevos significados en conjunción con las experiencias y los aprendizajes resultantes de aquellos tiempos.

Con fecha de 23 de abril de 1820 el Ayuntamiento de Cartaya acordaba, una vez tenía conocimiento de que por parte de la villa de Gibraleón «no huvo conformidad en separarse de la Jurisdicción que ha exercido privativa en dichos campos comunes", reunirse con el resto de los diputados de los pueblos del antiguo marquesado para convenir las medidas a tomar. Algunos días después volvía a insistir en un escrito dirigido a la Diputación Provincial sobre los perjuicios ocasionados por las autoridades de Gibraleón en torno a la jurisdicción del campo común, "que en todos tiempos ha tratado exercerla únicamente sin conocimiento ni intervención de los demás pueblos» ${ }^{49}$. Con fecha de 27 de abril de 1821 el Ayuntamiento de Cartaya manifestaba de nuevo su disgusto porque el de Gibraleón no había «hecho la invitación que se le ha prevenido a pesar del dilatado tiempo que ha transcurrido", en relación con el reconocimiento, la clasificación y la posterior división de los terrenos del campo común ${ }^{50}$. Habría que esperar a mayo de 1822 para que se llevase a cabo el reparto de esas tierras, después de que concluyeran las negociaciones de los distintos comisionados de los pueblos del antiguo marquesado "con toda tranquilidad y sosiego", y de que superaran los "graves inconvenientes» que se dieron durante su desarrollo ${ }^{51}$. El problema que se abría a continuación estaba relacionado con el reparto que tenía que hacer el Ayuntamiento de los terrenos que le habían correspondido «por mitad con el crédito público", de cuyo resultado venía a quedar "con muy poco terreno y malo» ${ }^{52}$, pero cuya gestión con las autoridades superiores ya no implicaba la salvaguarda de sus derechos en relación con la antigua cabeza del marquesado.

49. 28 de mayo de 1820. AMC, Actas Capitulares, leg. 10, s. fol.

50. AMC, Actas Capitulares, leg. 10, s. fol.

51. Los comisionados de Cartaya informaron de los resultados en la reunión capitular del 5 de mayo de 1822. AMC, Actas Capitulares, leg. 10, s. fol.

52. 8 de junio de 1822. AMC, Actas Capitulares, leg. 10, s. fol. 
La reimplantación del modelo constitucional gaditano también generaría un nuevo impulso del marco de apertura político en Villanueva de los Castillejos. Entre 1820 y 1823 se vislumbraba un escenario político dinámico y complejo en el que se implementaron, por ejemplo, mecanismos de toma de decisiones de carácter colectivo que no eran nuevos, pero que en ese contexto debieron de contribuir en no poca medida al desarrollo y consolidación de los conceptos y las prácticas políticas traídos por la contemporaneidad, entre los cuales quedaban identificados, además, los campos y las materias que debían ser tratados de manera conjunta. Los cabildos abiertos-acuerdos populares, como en ocasiones resultaban definidos en las fuentes- se centraron mayoritariamente en las esferas que concitaban la mayor preocupación e interés de su vecindario, como la recaudación y la distribución de cargas y gastos o el repartimiento del campo común ${ }^{53}$, circunstancia que permitía, asimismo, caracterizar, desde el ámbito local y a partir de realidades concretas, las nuevas dinámicas que se asociaban al proceso de politización y aperturismo del espacio público.

En todo caso, no hay que obviar la trascendencia que en ese escenario de configuración de nuevas prácticas e imaginarios políticos tendrían los procesos de elección celebrados anualmente para la conformación del Ayuntamiento, precisamente porque constituían una vía de participación pública sistematizada conforme a normativa, pero también porque permitían la manifestación, al menos en parte, del juego de intereses que caracterizaba a toda comunidad definida en términos políticos. No en vano, varios episodios inducen a pensar en un escenario no definido precisamente por la tranquilidad pública. El Ayuntamiento hacía constar en su sesión del 21 de diciembre de 1820 que eran muchas las reuniones nocturnas de hombres y mujeres en aquellos días, en las que, «después que se poseen de vino cantan coplas infamantes», y cuyo "escándalo» no respetaba ni «lo sagrado de la Autoridad Constitucional» 54 . A mediados de diciembre de 1821 se volvía a insistir en la necesidad de conservar el «buen orden y la armonía» del vecindario, particularmente en "estos días de la celebración de las elecciones de concejales", por lo que, tras observar que se estaban cantando por las noches "coplas satíricas e insultantes» dirigidas a particulares o sobre asuntos generales, el Ayuntamiento tomó algunas medidas con respecto al consumo de bebidas alcohólicas «hasta concluido el acto de elecciones» ${ }^{55}$.

Las prácticas y los aprendizajes asociados a las actuaciones políticas de los años de la guerra contra el francés volvían a tomar cuerpo durante la nueva etapa constitucional,

53. AMVC, Actas Capitulares, legs. 13, 14, s. fol.

54. AMVC, Actas Capitulares, leg. 13, s. fol.

55. AMVC, Actas Capitulares, leg. 13, s. fol. 
tanto en cuestiones formales y reglamentadas de carácter general como en aspectos menos tangibles relacionados, entre otros, con su ejercicio y concreción. En definitiva, en un marco de praxis política complejo, dinámico y densificado, las experiencias y los aprendizajes - también definidos en términos de complejidad y de amplificación en cuanto a sus actores y escenarios- resultaban claves, de una u otra manera, a la hora de marcar las líneas de acción concretas implementadas en diferentes comunidades locales de ámbito rural.

\section{CONSIDERACIONES FINALES: REPENSANDO EL PROCESO DE POLITIZACIÓN DESDE LOS MÁRGENES}

Como sostiene Jean-Philippe Luis, los términos politización y política moderna hacen referencia a la etapa coincidente con el final del Antiguo Régimen y la paulatina construcción del mundo nuevo propio de la contemporaneidad, proceso que no resulta lineal ni gradual, sino que, por el contrario, cuenta con momentos de ruptura, aceleración o retroceso, y se caracteriza siempre por presentar distintos ritmos en función del país (Luis, 2012: 51). La discusión no se ha centrado tanto en los perfiles del proceso -caracterizado en líneas generales por el cuestionamiento de las formas institucionales, jurídicas e ideológicas del poder existentes hasta entonces, por la posibilidad de que estas fuesen contestadas en el espacio público y, por tanto, que los individuos pudiesen conquistar el poder de manera legítima (Luis, 2012: 52)- sino en los agentes y los ámbitos que lo encabezaron, impulsaron o sostuvieron. Así, por ejemplo, como refiere Emilio La Parra, no es posible atribuir a la burguesía el protagonismo exclusivo del cambio político, toda vez que también tuvieron papeles destacados otros grupos sociales y estamentos, incluso sectores populares urbanos y rurales, en el caso del campesinado con especial relevancia en determinadas coyunturas (La Parra, 2012b: 17). Con todo, en líneas generales se ha destacado el protagonismo de los ámbitos urbanos como espacios de la política por excelencia, mientras que el campo, que mimetizaba los comportamientos de las ciudades más cercanas, si bien no quedaba al margen del aperturismo y la participación políticas, lo hacía de manera menos intensa y apreciable debido a los condicionantes de sus dimensiones más reducidas (Chust \& Rújula, 2017a: 44). Sin embargo, este trabajo ha permitido constatar, en línea con lo marcado por otras publicaciones dedicadas al mismo periodo (por ejemplo, Veiga, 2012, 2017a), que las comunidades locales de ámbito rural no siempre actuaron como meros agentes pasivos en este escenario de politización. De hecho, en los dos casos analizados la situación resultó muy diferente, toda vez que participaron activamente en ese proceso de cambio mediante, por ejemplo, la puesta en marcha de una rica y compleja práctica política que descansaba en una lectura no solo amplia, sino también específica, del marco político de fondo, y donde incluso resulta posible identificar 
procesos de aperturismo y concurrencia del vecindario que se anticiparon a la promulgación de la Constitución de Cádiz.

A fin de cuentas, en ambos ejemplos la politización y la densificación del espacio público se canalizaban desde enfoques y dinámicas concretas, en los que se daban la mano situaciones del pasado y del presente, elementos de influjo externo o de ascendencia interna a la comunidad, de ahí que no se ajustasen a una pauta o modelo de carácter unidireccional, que se proyectase exclusivamente de arriba abajo y que se encontrase definido y cerrado de antemano. Por el contrario, los caminos de la politización resultaban muy variados, y donde confluían en un mismo tiempo y espacio tendencias y aspiraciones diferentes e, incluso, enfrentadas: los casos analizados dan cuenta de la ampliación del campo de la política y de la extensión del espacio formal y simbólico en el que aquella se disputaba, y al que venían a confluir viejos y nuevos actores; pero ello no implica, al menos necesariamente, que esos nuevos instrumentos y dinámicas de participación en el ámbito público condujesen de manera automática y unidireccional hacia formulaciones democratizadoras que auspiciaban la igualdad en el acceso y la gestión de los recursos comunitarios, ya que abrigaron, asimismo, procesos de oligarquización respecto de ciertos recursos de la comunidad (como los episodios representados por la venta de bienes de propios o del fruto de la bellota), y de defensa de intereses particulares o de grupos concretos. En definitiva, las experiencias y los aprendizajes de las décadas iniciales del siglo XIX estarían conectados con realidades, prácticas, imaginarios y anhelos comunitarios -sin desdeñar sus posibles parcelaciones y pluralidades internas- de más largo alcance, todo lo cual terminaría resultando fundamental a la hora de materializar el nuevo escenario de la política abierto con la contemporaneidad.

\section{AGRADECIMIENTOS}

Este trabajo se enmarca dentro de los proyectos de investigación HAR2015-65991P y PID2019-105071GB-I00. Agradezco los comentarios realizados por los evaluadores anónimos de Historia Agraria, que han contribuido a mejorar sustancialmente el artículo.

\section{REFERENCIAS}

Acosta, F. \& CRUZ, S. (2012). Cultura política y participación popular bajo el sistema político de las Cortes de Cádiz: Una perspectiva desde la historia política de Andalucía. En M. A. Снамосно \& J. Lozano (Eds.), Sobre un hito jurídico: La Constitución 
de 1812: Reflexiones actuales, estados de la cuestión, debates historiográficos (pp. 373387). Jaén: Universidad de Jaén.

Burdiel, I. \& Romeo, M. C. (2001). Viejo y nuevo liberalismo en el proceso revolucionario. En P. PRESTON \& I. SAZ (Eds.), De la revolución liberal a la democracia parlamentaria:Valencia (1808-1975) (pp. 75-91). Madrid/Valencia: Biblioteca Nueva/Universitat de València.

Cabo, M. \& Veiga, X. R. (2011). La politización del campesinado en la época de la Restauración: Una perspectiva europea. En T. ORTEGA \& F. COBO (Eds.), La España rural, siglos XIX y XX: Aspectos políticos, sociales y culturales (pp. 21-58). Granada: Comares.

CAMPESE, F. J. (1999). El final de las elecciones de diputados y personeros del común en Sevilla (1803-1808). En J. L. Pereira, J. M. DE Bernardo \& J. M. GonZÁlez Beltrán (Coords.), V Reunión Científica Asociación Española de Historia Moderna II: La administración municipal en la Edad Moderna (pp. 83-90). Cádiz: Universidad de Cádiz.

Chust, M. \& Rújula, P. (2017a). La crisis de la Monarquía Hispánica (1808-1833): Las claves del periodo. En J. CANAL (Dir.), Historia contemporánea de España I: 1808-1931 (pp. 23-47). Barcelona: Taurus.

Chust, M. \& Rújula, P. (2017b). La crisis de la Monarquía Hispánica (1808-1833): La vida política. En J. CANAL (Dir.), Historia contemporánea de España I: 1808-1931 (pp. 49-102). Barcelona: Taurus.

CRUZ, S. (2012a). Campo frente a ciudad: Balance historiográfico de una larga historia sobre la politización de Andalucía. En S. CRUZ (Coord.), Andaluces contra el caciquismo: La construcción de una cultura democrática en la Restauración (pp. 25-48). Sevilla: Fundación Centro de Estudios Andaluces.

CRUZ, S. (2012b). Algunas consideraciones sobre debates historiográficos en la actualidad, a propósito de la historia local. En V. LeIs, L. MARTínez Aguilar \& L. RABANEDA (Coords.), Actas I Congreso de Historia de Linares (pp. 11-25). Jaén: Centro de Estudios Linarenses/Diputación Provincial de Jaén.

DemÉlas, M. D. \& GuERRA, F. X. (2008). Los orígenes de la democracia en España y América: El aprendizaje de la democracia representativa, 1808-1814. Lima: Fondo Editorial del Congreso del Perú/Oficina Nacional de Procesos Electorales.

FERNÁNDEZ TORRES, L. (2012). Evolución del concepto de partido en el tránsito del siglo XVIII al XIX: El caso de España (1780-1814). Historia Constitucional, (13), 433475.

GARCía MonERris, E. (2018). Todos son hombres, todos son ciudadanos y todos son responsables ante la ley: Los ayuntamientos como espacio de conflicto en tiempos de política y de constitución (1814-1823). En I. FRASQUET \& E. GARCía MONERRIs (Eds.), Tiempo de política, tiempo de constitución: La monarquía hispánica entre la revolución y la reacción (1780-1840) (pp. 55-85). Granada: Comares. 
García Monerris, E. \& García Monerris, C. (2009). Tiempo de liberalismo y de revolución: España en la primera mitad del siglo XIX. En I. FRASQUET \& A. SLEMIAN (Eds.), De las independencias iberoamericanas a los estados nacionales (1810-1850): 200 años de historia (pp. 263-293). Madrid/Frankfurt am Main: Iberoamericana/Vervuert.

Gómez Rivero, R. (2015). Las elecciones municipales en el Trienio Liberal. Madrid: Boletín Oficial del Estado.

Gordo, M. \& NúÑEZ MÁrQueZ, J. M. (1999). Roturación del monte, rozas y estabilidad social. En J. A. MÁrquez Domínguez (Dir.), Historia de la provincia de Huelva: Un análisis de los ámbitos municipales (pp. 625-640).Vol. II. Madrid: Mediterráneo.

GuERRA, F. X. (1998). De la política antigua a la política moderna: La revolución de la soberanía. En F. X. GUERRA et al., Los espacios públicos en Iberoamérica: Ambigüedades y problemas: Siglos XVIII-XIX (pp. 109-139). México, DF: Centro Frances de Estudios Mexicanos y Centroamericanos/Fondo de Cultura Económica.

GuZMÁn PÉREZ, M. (2019). Introducción [Dossier Cultura política de sociedades en transición: México y Centroamérica, 1780-1851]. Rubrica Contemporanea, 8 (15), 1-3. HERRERA, A. (2012). Las categorías conceptuales y el debate teórico actual en torno a la construcción de la democracia: Su aplicación a la historia contemporánea de Andalucía. En S. Cruz (Coord.), Andaluces contra el caciquismo: La construcción de una cultura democrática en la Restauración (pp. 51-69). Sevilla: Fundación Centro de Estudios Andaluces.

Herrera, A. \& MARKoff, J. (2013). Presentación [Dossier Democracia y mundo rural en España]. Ayer, (89), 13-19.

Herrera, A., Markoff, J. \& Villa, I. (2013). La democratización del mundo rural en España en los albores del siglo xx: Una historia poco conocida. Ayer, (89), 21-42.

Horrach, J. A. (2009). Sobre el concepto de ciudadanía: Historia y modelos. Factótum, (6), 1-22

La Parra, E. (2012a). Presentación [Dossier La Guerra de la Independencia], Ayer, (86), 13-24.

La PARra, E. (2012b). Politización y movilización popular en España. En E. LA PARRA et al., El nacimiento de la política en España (1808-1869) (pp. 11-32). Madrid: Pablo Iglesias.

LuIs, J. P. (2009). Cuestiones sobre el origen de la modernidad política en España (finales del siglo XVIII-1868). Revista de Historia ferónimo Zurita, (84), 247-276.

LuIs, J. P. (2012). España y los modelos occidentales de nacimiento de la política moderna. En E. LA PARRA et al., El nacimiento de la política en España (1808-1869) (pp. 5168). Madrid: Pablo Iglesias.

Mira, A. (2008). La población de Cartaya a lo largo de la historia. En J. ViLlegas (Coord.), Cartaya, la villa y el tiempo: Recopilación de trabajos históricos de los miem- 
bros de la Asociación Cultural Carteia (pp. 371-425). Huelva: Diputación Provincial de Huelva.

Mira, A., Villegas, J. \& Suardíaz, A. (2010). La batalla de Castillejos y la guerra de la Independencia en el Andévalo occidental. Huelva: Diputación de Huelva.

Moliner, A. (2012). En torno al Trienio Constitucional (1820-1823). Rubrica Contemporanea, 1 (1), 29-45.

MoRÁN, R. (2011). «Abajo todo: fuera señoríos y sus efectos»: El Decreto de 6 de agosto de 1811. Revista de derecho político, (82), 241-262.

PÉrez Ledesma, M. (2012). La invención de la ciudadanía moderna. En E. LA PARRA et al., El nacimiento de la política en España (1808-1869) (pp. 33-49). Madrid: Pablo Iglesias.

PosADA, E. (2008). Sorpresas de la historia: Independencia y democratización en Hispanoamérica. Revista de Occidente, (326-327), 109-125.

RuIz GonZÁlez, J. E. (1999). Huelva, según las relaciones enviadas por los párrocos al geógrafo real Tomás López en el siglo XVIII. Huelva: Diputación Provincial de Huelva.

Rújula, P. (2008). La guerra como aprendizaje político: De la guerra de la independencia a las guerras carlistas. En El carlismo en su tiempo: Geografías de la contrarrevolución: I fornadas de Estudio del Carlismo, 18-21 septiembre 2007, Estella:Actas (pp. 4164). Pamplona: Gobierno de Navarra.

Rúulua, P. (2012). La densificación del universo político popular durante la Guerra de la Independencia. En P. Rújula \& J. CANAL (Eds.). Guerra de ideas: Política y cultura en la España de la Guerra de la Independencia (pp. 173-190). Zaragoza/Madrid: Institución Fernando el Católico/Marcial Pons.

Rúulua, P. \& Chust, M. (2020). El Trienio Liberal en la monarquía hispánica: Revolución e independencia (1820-1823). Madrid: Los Libros de la Catarata.

Rújula, P. \& RAmón, J. (2017). Introducción: Paradojas de la reacción: Continuidades, vías muertas y procesos de modernización en el universo reaccionario del XIX. En P. RúJula \& J. RAMÓN (Eds.), El desafío de la revolución: Reaccionarios, antiliberales y contrarrevolucionarios (siglos XVIII y XIX). (pp. 1-10). Granada: Comares.

SALDAÑA, J. (2016a). Más allá de Cádiz: La experiencia como aprendizaje en el ámbito político municipal (1814-1814). En G. Butrón \& A. RAmos (Eds.), Cádiz, escuela política: Hombres e ideas más allá de 1814. (pp. 213-240). Madrid: Sílex.

SALDAÑA, J. (2016b). La restauración absolutista y el poder municipal: Aproximaciones a 1814 desde el suroeste andaluz. Trocadero, (28), 79-99.

Salvatto, F. G. \& Carzolio, M. I. (2015). Naturaleza y ciudadanía en la España Moderna: De la representación del súbdito a los albores de la ciudadanía contemporánea (siglos XVII-XIX). Almanack, (11), 670-706.

Soto, D. \& HERRERA, A. (2014). El conflicto agrario en la historia contemporánea de España: Nuevas perspectivas de análisis. Vínculos de Historia, (3), 75-100. 
Thomson, G. (2014). El nacimiento de la política moderna en España: Democracia, asociación y revolución, 1854-75. Granada: Comares.

VeIGA, X. R. (2008). Poder e representación política en Galiza (1790-1856): Avance de investigación e algunhas premisas de partida. En X. L. AxeITos, E. GRANDío \& R. VILlares (Eds.), A patria enteira: Homenaxe a Xosé Ramón Barreiro Fernández (pp. 381-398). Santiago de Compostela: Concello da Cultura Galega/Universidade de Santiago de Compostela.

VEIGA, X. R. (2012). Signos, indicios, pistas: politización en la Galicia de la revolución y la contrarrevolución (1808-1843). En R. López FACAL \& M. CABo (Eds.), De la idea a la identidad: Estudios sobre nacionalismos y procesos de nacionalización: Estudios en homenaje a fusto Beramendi (pp. 183-197). Granada: Comares.

VeIga, X. R. (2017a). Poder e política na Galiza vilega 1790-1833: Provincias de Lugo e Mondoñedo. Santiago de Compostela: Bolada.

Veiga, X. R. (2017b). Poderes y contrapoderes en Galicia, 1790-1833. En A. Ramos \& D. RePETO (Eds.), Poder, contrapoder y sus representaciones: XVII Encuentro de la Ilustración al Romanticismo: España, Europa y América (1750-1850) (pp. 137-150). Cádiz: Universidad de Cádiz.

Vega, J. DE (1995). Huelva a fines del Antiguo Régimen, 1750-1833. Huelva: Diputación Provincial de Huelva.

WINDLER, C. (1997). Élites locales, señores, reformistas: Redes clientelares y monarquía hacia finales del Antiguo Régimen. Córdoba/Sevilla: Universidad de Córdoba/Universidad de Sevilla.

WINDLER, C. (2007). Reformismo señorial y reformismo monárquico en Andalucía (c. 1760-1808). En F. ANdúJar \& J. P. Díaz López (Coords.), Los señoríos en la Andalucía moderna: El marquesado de los Vélez (pp. 117-128). Almería: Instituto de Estudios Almerienses. 